\title{
Recerca geològica i mineralògica per la comarca de I'Alt Palància: des de Sot de Ferrer i Soneja a Castellnovo, Peñalba i a Segorbe / Sogorb
}

\author{
Josep Maria Mata-Perelló \\ Joaquim Sanz Balagué \\ Jaume Vilaltella Farràs
}

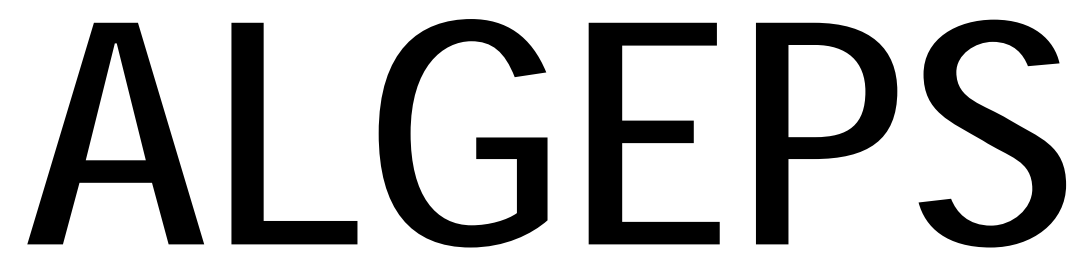

\section{REVISTA DE GEOLOGIA}

\section{n. 4}

DESEMBRE 2014 


\title{
RECERCA GEOLÒGICA I MINERALÒGICA PER LA COMARCA DE L'ALT PALÀNCIA: DES DE SOT DE FERRER I SONEJA A CASTELLNOVO, PEÑALBA I A SEGORBE / SOGORB
}

\author{
Josep Maria Mata-Perelló \\ Museu de geologia Valentí Masachs, Escola Politècnica Superior d'Enginyeria de Manresa \\ (EPSEM), Universitat Politècnica de Catalunya · BarcelonaTech (UPC), 08272 Manresa, Spain
}

\section{Joaquim Sanz Balagué}

Departament d'Enginyeria Minera i Recursos Naturals (EMRN), Escola Politècnica Superior d'Enginyeria de Manresa (EPSEM), Universitat Politècnica de Catalunya · BarcelonaTech (UPC), 08272 Manresa, Spain

Jaume Vilaltella Farràs

Paraules clau: Patrimoni geològic i miner; Sistema ibèric; País Valencià

\begin{abstract}
Resum
Itinerari realitzat el dia 8 de desembre del 2013. Aquest itinerari geològic i mineralògic, discorrerà íntegrament dintre del Sistema Ibèric. I més concretament, bona part del recorregut es situarà dintre dels denominats relleus triàsics de Sagunt (RIBA et altri, 1976), del Sistema Ibèric. Així, en la major part dels trajectes anirem trobant afloraments dels diferents materials triàsics. Tot i això, també trobarem afloraments dels materials del Juràssic i del Cretàcic.
\end{abstract}

Per d'altra banda, cal dir que tot i així, malgrat trobar-se força lluny de la denominada Zona d'Enllaç, aquesta zona encara es troba afectada per fractures de direcció catalana. Efectivament, al llarg del recorregut, anirem trobant diverses estructures d'arrumbament clarament català, de direccions predominants NE - SW i NNE - SSW. Aquestes direccions són perpendiculars amb les ibèriques (NW - SE).

Al principi, per les immediacions de Sot de Ferrer, predominaran els materials del Keuper (amb afloraments de guixos $i$ argiles). Després anirem trobant afloraments dels altres trams del Triàsic, així com del Juràssic i del Cretàcic

Finalment, cal dir que aquest itinerari transitarà per una sola comarca del País Valencià, concretament per la de l'Alt Palància. Així s'iniciarà a Sot de Ferrer per a finalitzar al terme de Segorbe / Sogorb, la capital comarcal. 


\section{Objectius fonamentals}

Dintre d'aquest itinerari, ens fixarem els següents objectius, d'acord amb el sentit de la marxa:

1.- Estudi i observació dels materials paleozoics (del Carbonífer) i dels mesozoics (del Triàsic, quasi exclusivament), que constitueixen el Sistema Ibèric, per on discorrerà la totalitat del recorregut de l'itinerari, entre les poblacions de Sot de Ferrer i Segorbe / Sogorb. Tanmateix, a diferents indrets del recorregut, trobarem afloraments de materials carbonatats del Juràssic.

2.- Observació de les estructures del Sistema Ibèric, dintre dels Relleus Triàsics de Sagunt, per on discorrerà tot aquest itinerari. En aquest recorregut es veuran diverses fractures de clara direcció catalana (NE - SW i NNE - SSW), entrecreuant-se amb altres de direcció ibèrica (NW $-\mathrm{SE})$.

3.- Estudi de diverses mineralitzacions situades entre els materials triàsics del Sistema Ibèric. Entre aquestes, farem esment de les següents, d'acord amb el sentit de la marxa de l'itinerari:

3A) Mineralitzacions evaporítiques, situades a Segorbe / Sogorb i a Soneja / Sonèixer (ambdues a l'Alt Palància), situades entre els materials triàsics del Keuper.

3B) Mineralitzacions cupríferes associades a "red-beds", situades a Castellnovo situades entre els materials triàsics del Buntsandsteim.

4.- Observació d'algunes explotacions realitzades a "cel obert" o subterrànies, antigues o actuals, com les següents:

4A) Explotacions dels nivells guixosos del Keuper, situades al terme de Segorbe, però prop del Soneja / Sonèixer a la comarca de l'Alt Palància.

4B) Observació de antigues explotacions de minerals de coure, situades al terme de Castellnovo, entre altres indrets

5.- Observació de l'impacte produït per les explotacions anteriors sobre el medi natural, i si s'escau de les restauracions dutes a terme per a reduir aquest impacte.

6.- Observació dels diferents indrets relacionats amb el nostre Patrimoni Geològic que anirem trobant al llarg del recorregut de l'itinerari, i en especial dels que puguin ésser catalogats com a LIG (Llocs d'Interès Geològic.

7.- Observació dels diferents indrets relacionats amb el nostre Patrimoni Miner que anirem trobant al llarg del recorregut de l'itinerari, i en especial dels que puguin ésser catalogats com a LIPM (Lloc d'Interès del Patrimoni Miner, com els Forns de Guix de Sot de Ferrer i de Segorbe / Sogorb)

\section{Antecedents}

No coneixem l'existència de cap antecedent bibliogràfics relatiu al conjunt d'aquest itinerari. Tot i així, hi ha alguns antecedents parcials nostres: MATA-PERELLÓ (2003, 2004 i 2010). Així com de MATA - PERELLÓ i VILALTELLA FARRÀS (2013). També farem esment d'un treball nostre molt recent. Es tracta de MATA - PERELLÓ i VILALTELLA FARRÀS (2013).

Pel que fa a l'estudi de les mineralitzacions situades al llarg del recorregut, farem un especial esment del treball de MATA-PERELLÓ (1984), relatiu a les mineralitzacions que s'estenen per les comarques per les quals discorre el recorregut de l'itinerari. 
Pel que fa a l'estructura geològica dels indrets pels quals discorrerà el recorregut de l'itinerari, farem esment de dos treballs generals, relatius al conjunt dels Països Catalans: GUIMERÀ et altri (1992), i RIBA et altri (1976). Igualment, cal fer esment dels fulls del Mapa Geológico de España corresponents a la zona: IGME (1074a i b).

També, pel que fa al Patrimoni Miner, farem referencia d'un treball nostre recent: MATAPERELLÓ et altri (2012).

Tots aquests treballs esmentats, figuraran per ordre alfabètic a l'apartat dedicat a la bibliografia.

\section{Recorregut de l'itinerari}

El recorregut d'aquest itinerari comença a la comarca de I'Alt Palància, prop de la població de Sot de Ferrer, encara que dintre del terme de Segorbe / Sogorb, on es farà la primera parada del recorregut del present itinerari. Aquesta aturada la realitzarem a unes antigues explotacions de guix.

A continuació, el recorregut es dirigirà cap el Nord, seguint la carretera nacional $\mathrm{N}-234$ (en el seu recorregut antic), anant cap a la població de Soneja / Sonèixer. Abans d'arribar-hi es faran diverses aturades.

Després. per una carretera local (i posteriorment per la CV - 200), s'anirà cap a la població de Castellnovo, per on es faran diverses aturades. A partir d'aquí, s'escau, es farà una fillola per tal d'anar cap a les immediacions de la població de la Vall de Almonacid, passant abans per Peñalba, seguint la carretera CV - 215. Posteriorment, es retornarà cap a les immediacions de Segorbe / Sogorb, per on es faran les darreres aturades, finalitzant el recorregut d'aquest itinerari.

\section{Advertiments previs}

Com en altres recorreguts de RECERCA GEOLÒGICA I MINERALÒGICA ..., si es disposa del temps suficient, poden efectuar-se passant per totes les parades i filloles. En cas contrari, recomanem prescindir de les anomenades PARADES - CONDICIONALS.

També cal tenir en conte que una part del recorregut final de l'itinerari, es realitzarà per camins de terra, per la qual cosa caldrà prendre les degudes precaucions..

Cal tenir, com sempre, una cura molt especial de respecte a la natura, al llarg de tot el recorregut de l'itinerari, i també fora d'ell.

\section{Descripció de l'itinerari}

Com en altres itineraris, a continuació veurem una sèrie de "parades o estacions". En cada una d'elles es farà un breu comentari, ja sigui de caràcter geològic, geomorfològic o mineralògic, segons s'escaigui. Per d'altra banda, darrera del nom de l'indret (o de la parada), situarem entre parèntesi el número del Mapa Topogràfic, a escala 1:50.000, on es troba l'indret de l'aturada.

En aquesta ocasió, utilitzarem dos fulls de l'esmentat mapa topogràfic; concretament, el 640 (dit ara d'Onda i anteriorment de Segorbe) i el 668 (o de Sagunt). Aquests fulls han estat publicats pel Instituto Geográfico y Catastral de España. 
Així doncs, la relació general de les aturades que constitueixen aquest itinerari, d'acord amb el sentit de la marxa, és el següent:

\subsection{Parada 1. Explotacions de guix de les immediacions de Sot de Ferrer, (terme de Segorbe I Sogorb, comarca de I'Alt Palància). (Full 668).}

L'inici del recorregut el farem front de Sot de Ferrer, sobre la carretera N-234. Des d'aquí, ens caldrà anar cap al Nord, cap a Segorbe / Sogorb. Però, a poca distancia de la Venta Millán, farem la primera aturada, quasi a la bora de la carretera. Així, des del seu inici haurem recorregut $0 ` 5 \mathrm{Km}$, per tal d'arribar fins aquí on som ara.

En aquest recorregut, haurem trobat exclusivament afloraments dels materials triàsics del Keuper, amb nivells de guixos i d'argiles. Els primers han estat explotats a l'indret de la present aturada. (fotografia 1).

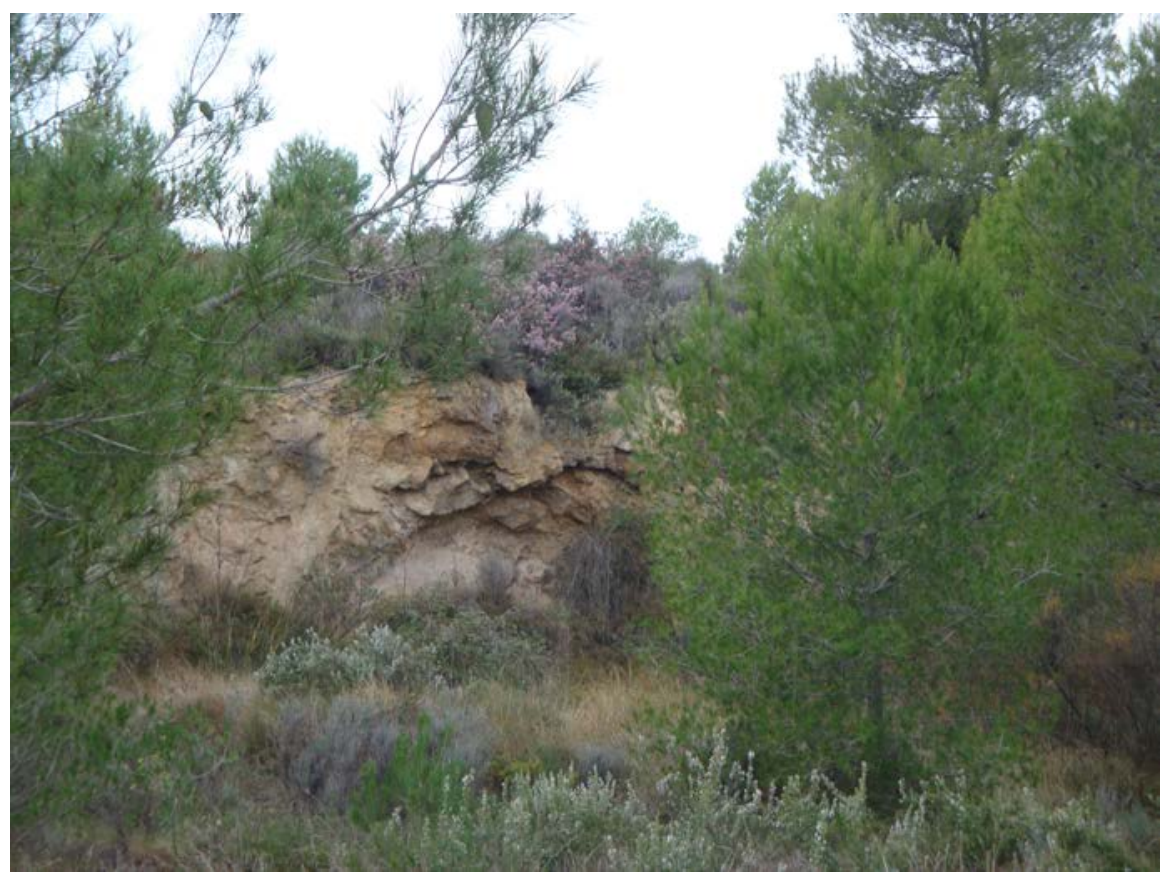

FOTOGRAFIA 1. Guixera de les immediacions de la Venta de Millán. Desembre, 2010

\subsection{Parada 2. Forns de guix de les immediacions de Sot de Ferrer, (terme de Segorbe I Sogorb, comarca de l'Alt Palància). (Full 668).}

Després de realitzar l'aturada anterior, cal fer un breu recorregut per la carretera $N-230$, continuat anat cap a Segorbe / Sogorb. A molt poca distancia de I'anterior parada, en farem una altra, a menys de $0 ` 5 \mathrm{Km}$, per tal d'arribar fins aquí on som ara.

En aquest recorregut hem anat trobant afloraments dels materials triàsics del Keuper, amb nivells de gresos y de guixos, fonamentalment. Aquests són els materials que apareixen a 
I'indret de l'aturada. Com a les aturades anteriors, ens trobem situats dintre del Sistema Ibèric, entre afloraments dels materials triàsics.

En aquest indret hi ha les restes d'uns antics forns de guix (forns d'algeps). En ell s'utilitzaven els materials guixosos extrets pels voltants. Els forns es troben en un precari estat de conservació. Tot i així, formen part del Patrimoni Miner de la Comarca de I'Alt Palància. (fotografia 2).

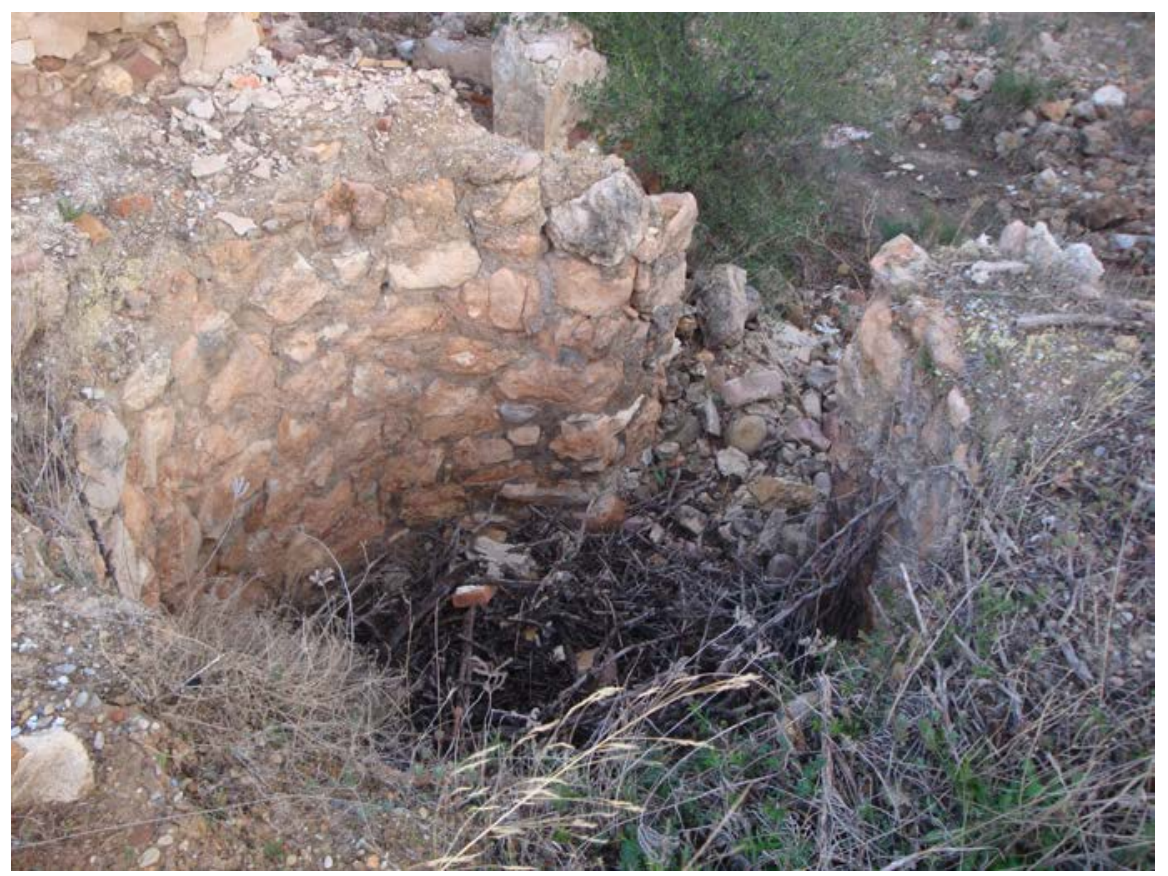

FOTOGRAFIA 2. Un aspecte d'un dels Fons de Guix de Sot de Ferrer. Desembre, 2010

\subsection{Parada 3 - condicional. Forns de guix de Segorbe, (Terme municipal de Segorbe I Sogorb, comarca de I’Alt Palància).(Full 668).}

Després de fer la parada anterior, cal fer un curt recorregut per la carretera $\mathrm{N}-234$, anant cap el Nord, cap el proper poble de Segorbe / Sogorb. Així, a menys de 0’2 Km de la parada anterior, en podem fer una altra.

En aquest recorregut, hem tornat a trobar afloraments dels materials triàsics del Keuper. Aquests materials es troben constituïts per nivells de guixos i de lutites. Els guixos han estat explotats a diferents indrets, prop de la carretera. Així, per arreu, es veuen restes d'aquestes explotacions.

Per d'altra banda, també es fan paleses les restes dels Forns de Guix (o Forns d'Algeps), molt similars als de la parada anterior. Així, a l'indret de la present aturada se'n troben dos d'aquests forns. Aquets, a l'igual que els anteriors, formen part del Patrimoni Miner de la Comarca de I'Alt Palància. (fotografia 3). 


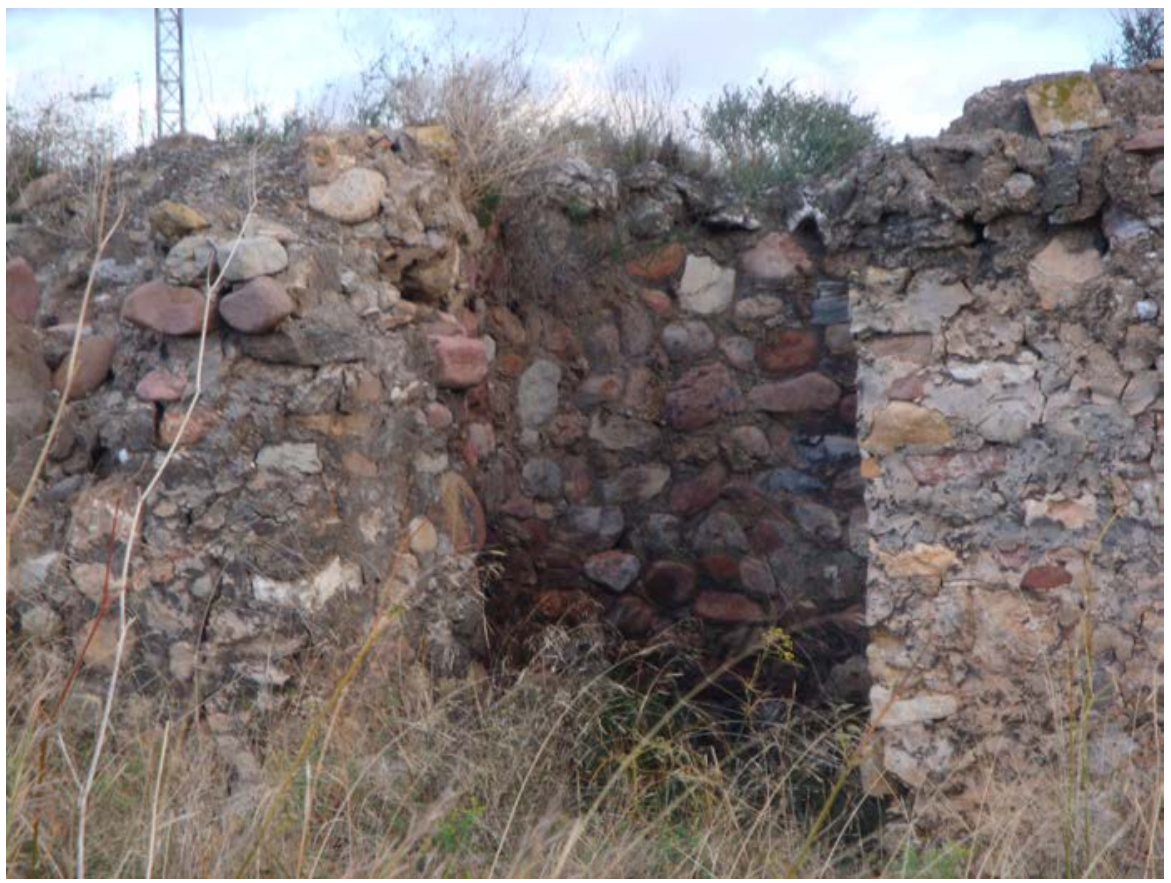

FOTOGRAFIA 3. Un aspecte d'un dels Fons de Guix de Segorbe. Desembre, 2010

\subsection{PARADA 4. Algepsar de Soneja / Sonèixer, (terme municipal de Segorbe I Sogorb, comarca de I’Alt Palància).(Full 668).}

Des de la parada anterior, cal fer un breu recorregut anant cap el Nord, per la carretera N 234. Quasi en arribar front a la fàbrica de guix, cal agafar un camí de terra que es dirigeix cap a ponent. Aquest camí es troba poc abans de sobrepassar el pont de l'Autovia. Així, a uns 200 metres de la carretera y a uns 500 metres de la parada anterior, en farem una altra.

En aquest recorregut, haurem tornat a trobar afloraments dels materials triàsics del Keuper. Aquests han estat explotats a diferents indrets, com al lloc de present aturada. Aquí hi ha una explotació actual, realitzada a cel obert.( fotografia 4).

per d'altra banda, entre els minerals presents, i a més a més del mateix guix, també es troba hemihedrita (analitzable per difractometría de rx). tanmateix, es fa fàcilment observable l'anhidrita, molt clara i espàtica, de vegades amb cares de més de $2 \mathrm{~cm}$ d'aresta.

Pel que fa al primer mineral esmentat més amunt (al GUIX), se'n pot trobar de diverses formes. Així, n'hi ha d'espàtica, fibrosa i massiva; les dues primeres són sempre de caràcter secundari, sempre formades a partir de la tercera, per dissolució a partir de les aigües superficial. Les formes més massives corresponen al denominat "guix primari"

També hi ha abundants minerals d'origen diagenètic, entre aquests guixos com: dolomita negra (antigament batejada com a teruelita), quars roig (en la seva varietat de jacint de compostel.la), i pirita (en piritoedres molt petits).

Finalment, cal dir que per diferents zones de la pedrera, es poden veure fractures de clara direcció catalana (aproximadament NE - SW i de vegades NNE - SSW). Aquestes fractures afecten als materials del Keuper. 


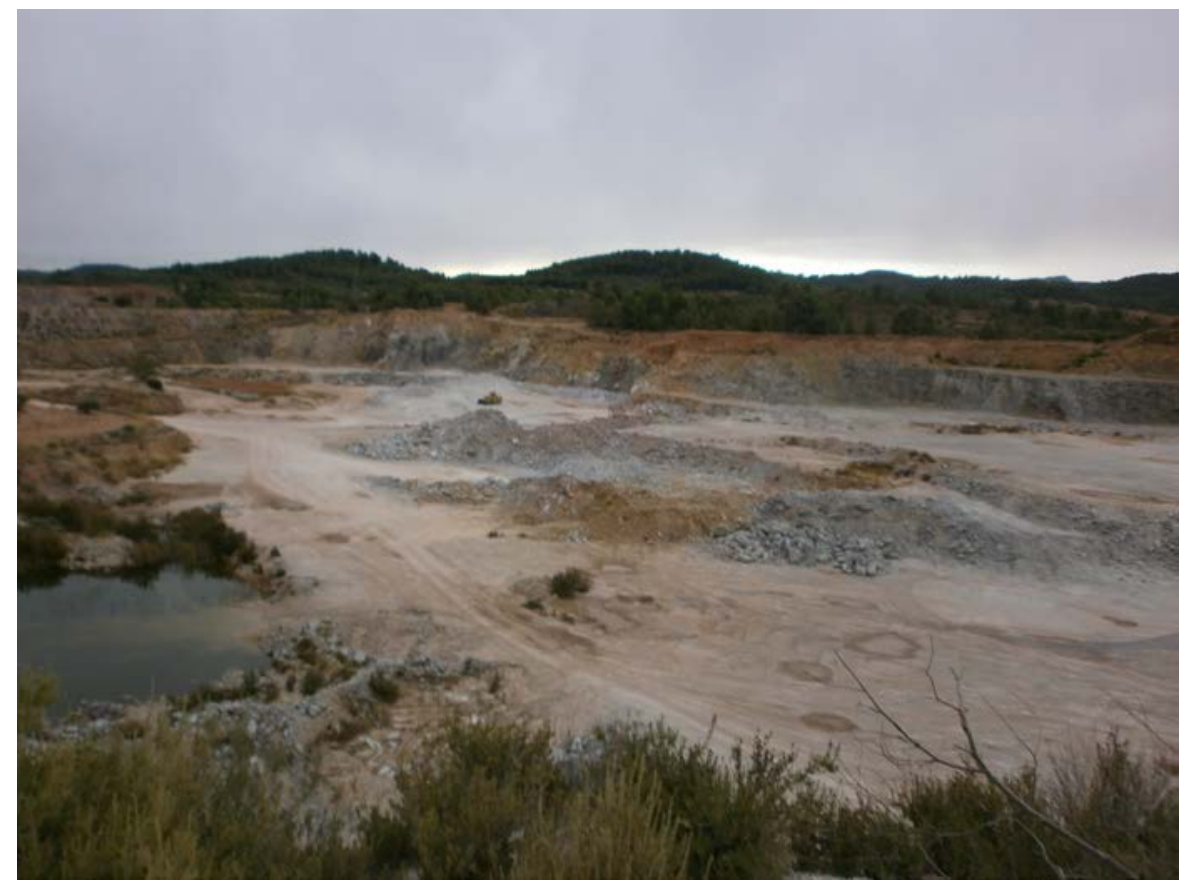

FOTOGRAFIA 4. Explotació de guixos prop de Soneja, terme de Segorbe . Novembre, 2013

\subsection{Parada 5 - condicional. Explotacions de calcària. Carretera de Soneja a Castellnovo, (terme municipal de Castellnovo, comarca de l'Alt Palància).(Full 640).}

Després de fer la parada anterior, cal arribar fins a la població de Soneja / Sonèixer, per tal de continuar per una carretera local (sense numeració) cap a la carretera que uneix Castellnovo amb Almedijar. Així, seguint per aquesta carretera local, a uns $4 \mathrm{Km}$ de Soneja, farem una nova aturada, després de recórrer uns $6 \mathrm{Km}$ des de la parada anterior.

En aquest recorregut, hem anat trobant afloraments dels materials mesozoics del Triàsic. Inicialment, haurem vist afloraments dels nivells argilosos i guixosos del Keuper. Posteriorment, haurem trobat afloraments dels materials carbonatats del Muschelkalk (del Triàsic Mig) i també del Juràssic. En qualsevol cas, ens haurem estat desplaçant dintre del Sistema Ibèric. Tanmateix, podem dir que ens trobem situats, des de l'inici del recorregut, dintre dels anomenats relleus triàsics de Sagunt (RIBA et altri, 1976).

En aquest indret hi havia una antiga explotació dels materials carbonatats (fonamentalment calcaris) acabats d'esmentar; en concret, es tractat dels nivells de les calcàries triàsiques del Muschelkalk. (fotografia 5). 


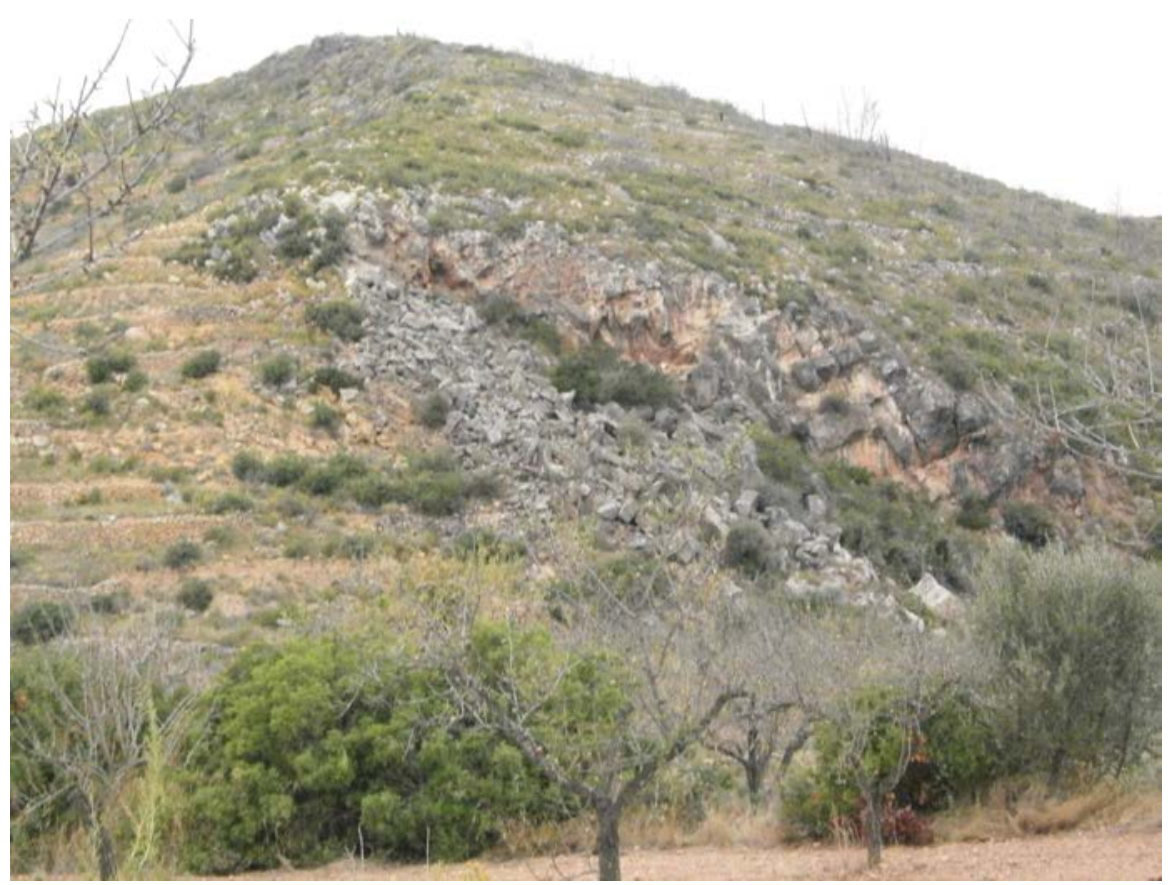

FOTOGRAFIA 5. Explotació de calcaries del Muschelkalk,. Novembre, 2013

\subsection{Parada 6. La mina, (terme municipal de Castellnovo, comarca de l'Alt Palància).(Full 640).}

Després de fer la parada anterior, cal acabar d'arribar fins a la carretera que comunica Castellnovo amb Almedijar (la CV - 200). En trobar-la, ens caldrà anar cap a la primera població esmentada. Així, en arribar a Castellnovo, farem una nova aturada, just a l'entrada de la població, al paratge anomenat "la mina". Així, des de la parada anterior, haurem recorregut uns $5 \mathrm{Km}$ més, fins arribar on ara som.

En aquest recorregut, hem anat trobant afloraments dels materials esmentats a l'aturada anterior. Efectivament, ens trobem situats dintre del Sistema Ibèric; i en concret, dintre dels relleus triàsics de Sagunt (RIBA et altri, 1976).

En aquest indret, on ara hi ha un parc, hi havia les instal-lacions d'una antiga mina de coure, situada prop d'on som. Estava relacionada amb una mineralització cuprífera associada a "red bed". Estava situada en un aflorament del nivells triàsics del Buntsandsteim. Entre els minerals presents, cal fer esment de l'atzurita i de la malaquita, formades a partir de l'alteració dels sulfurs, com la calcopirita.

A l'actualitat, sols queda el record de la mina, el seu topònim i una sèrie de plafons situats al parc.

\subsection{Parada 7. Algepsar de Peñalba, Km 18, (terme municipal de Peñalba, comarca de I’Alt Palància).(Full 668).}


Després de fer la parada anterior, cal travessar la població de Castellnovo, anat després cap a les immediacions de Segorbe / Sogorb, per tal d'iniciar una fillola anant cap a ponent, per la carretera CV - 215. Així aviat arribarem a Peñalba. Després de sobrepassar la població, farem una nova aturada prop del $\mathrm{Km} 18$ de la carretera, a uns $4 \mathrm{Km}$ de la parada anterior.

En aquest recorregut, hem trobat afloraments dels materials esmentats a les aturades anteriors. Tot i així, en aquest indret hi ha un aflorament dels materials triàsics del Keuper, amb presència de nivells de guixos $\mathrm{i}$ d'argiles. Els primers han estat mínimament explotats en aquest indret. (fotografia 7).

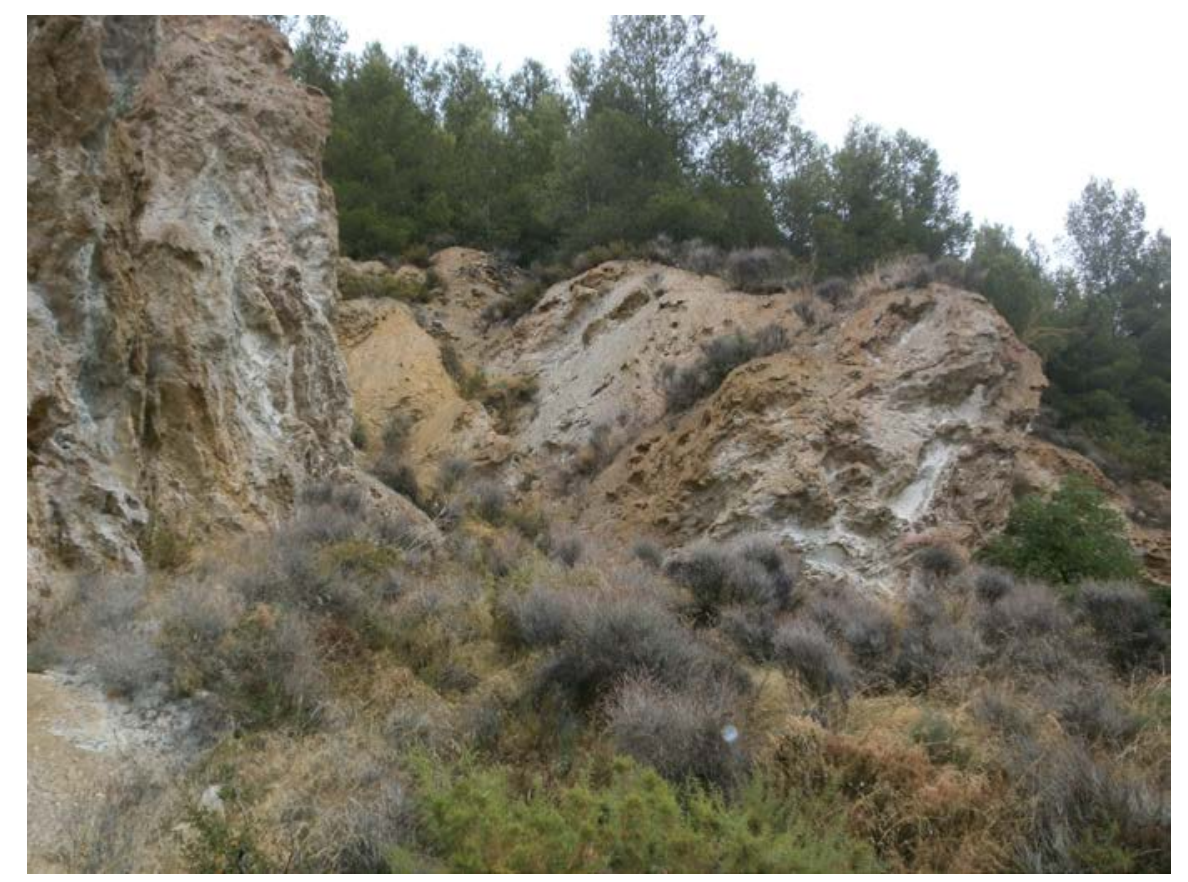

FOTOGRAFIA 7. Aflorament explotat dels guixos triàsics del Keuper a Peñalba. Novembre, 2013

\subsection{Parada 8 - condicional. Castell de la Vall d'Almonacid $I$, (terme municipal de la Vall d'Almonacid, comarca de I’Alt Palància).(Full 668).}

Després de fer la parada anterior, cal continuar per la carretera CV -215 , continuant fent la fillola. Així arribarem a la Vall d'Almonacid. Aquí farem una nova aturada, si s'escau, a uns 6 $\mathrm{Km}$ de la parada anterior.

En aquest recorregut, haurem transitat en inicialment entre afloraments dels materials triàsics del Keuper. Després d'arribar a Segorbe, fins a l'indret de l'aturada, haurem vist afloraments dels materials carbonatats del Juràssic (fonamentalment del Liàsic). Tots aquests materials es situen dintre del Sistema Ibèric. Cal dir que es troben afectats per sovint fractures, de direcció "catalana" i de direcció "ibèrica".

Des d'aquest indret, mirant cap a llevant es pot veure un aflorament dels materials carbonats del Triàsic Mig, del Muschelkalk. Així, veurem un nivell d'aquests materials carbonatats sobre el que s'assenta el castell. (fotografia 8). 


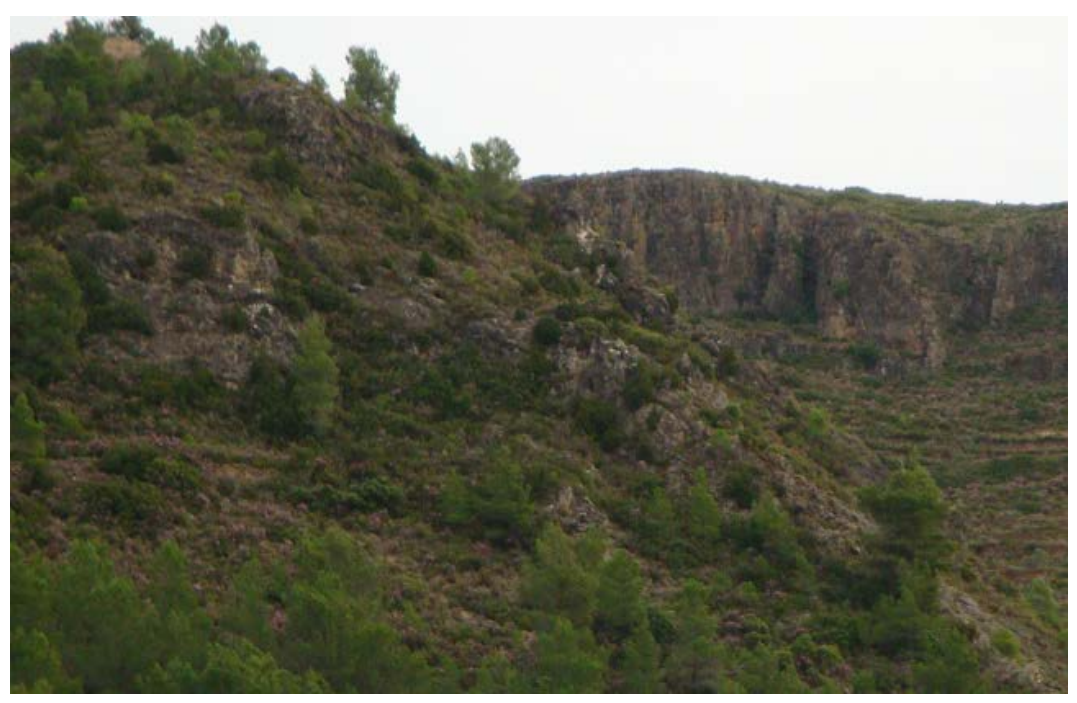

FOTOGRAFIA 8. Afloraments del Muschelkalk sota del Castell de la Vall d'Almonacid. Desembre del 2010

\subsection{Parada 9 - condicional. Argilera de Segorbe, (terme municipal de Segorbe, comarca de I’Alt Palància).(Full 668).}

Després de fer la parada anterior, cal tornar enrere, per tal de retornar cap a la població de Segorbe / Sogorb, circulant per la carretera CV - 215. Quasi en arribar a la capital comarcal, es farà patent una gran explotació argilosa, per on farem la present aturada, a uns $12 \mathrm{Km}$ de la parada anteriorment realitzada (fotografia 9).

En aquest recorregut haurem trobat els materials esmentats en el recorregut anterior. Tot i així, en arribar a l'indret de la present aturada, es faran palesos uns afloraments de materials cenozoics neògens del Miocè. Aquests materials han estat explotats a diferents indrets propers a la capital comarcal.

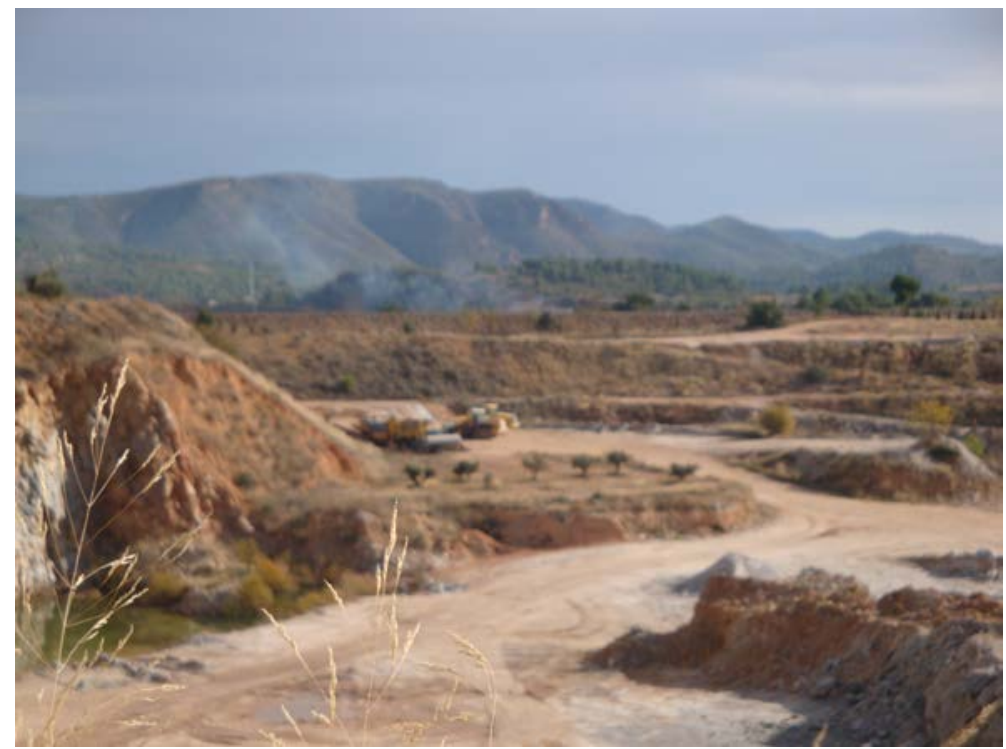

FOTOGRAFIA 9. Explotacions de les argiles del Miocè a Segorbe . Desembre del 2010. 


\subsection{Parada 10. Fuente de los 50 caños, (terme municipal de Segorbe, comarca de I’Alt Palància).(Full 668).}

Després de fer la parada anterior, cal acabar d'arribar fins a Segorbe / Sogorb, per tal d'iniciar de fer una nova aturada, la darrera del recorregut d'aquest itinerari. Així, ens caldrà agafar la carretera que es dirigeix cap a Navajas; però en sortir de la capital comarcal, ens caldrà anar cap a l'indret on hi ha el paratge de la Fuente de los 50 caños. En arribar-hi, farem la darrera aturada del recorregut d'aquest itinerari. Així, haurem efectuat un nou recorregut, proper ara als $3 \mathrm{Km}$ des de la parada anterior.

En aquest recorregut, hem anat trobant afloraments dels materials esmentats a les aturades anteriors. Així, ara haurem trobat afloraments dels materials miocènics. També, haurem trobat afloraments dels materials mesozoics del Sistema Ibèric, on ens trobem situats des de l'inici del recorregut.

En aquest indret, hi ha unes interessants surgències d'aigua, canalitzades cap a 50 fonts. Es troben situades molt prop del riu Palància, entre els afloraments dels travertins del Pleistocè, que apareixen prop del riu. Cal dir que és un indret molt interessant, tot i el seu caràcter antròpic (fotografia 10).

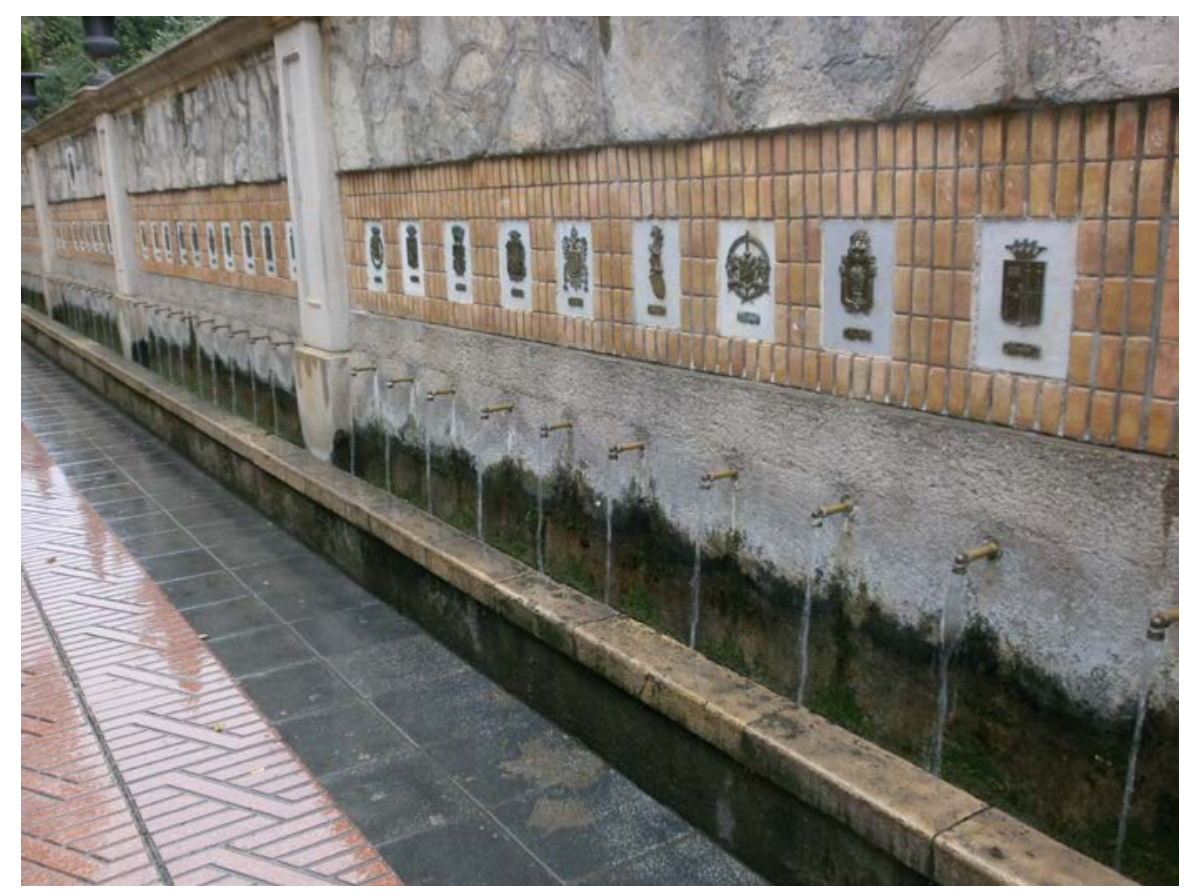

FOTOGRAFIA 10. El paratge de la Fuente de los 50 caños. Segorbe. Novembre del 2013.

En aquest indret finalitza l'itinerari. 


\section{BIBLIOGRAFIA}

GUIMERÀ, J. et altri /1992).- Geologia (II), Història Natural dels Països Catalans, Vol.2, 547 pag. Enciclopèdia Catalana, S,A,, Barcelona

I.G.M.E (1974).- Mapa Geológico de España, a escala 1:50.000, $2^{a}$ Sèrie. Hoja i memória no 640 (Segorbe). Inst. Geol Minero de España. Minist. Indústria. Madrid

I.G.M.E (1974).- Mapa Geológico de España, a escala 1:50.000, $2^{a}$ Serie. Hoja i memória ${ }^{\circ}$ 668 (Sagunto). Inst. Geol Minero de España. Minist. Indústria. Madrid

LOPEZ, J. i ARCHE, A. (1986).- Estratigrafia del Permico y Triàsico, en facies Buntsandsteim y Muschelkalk, en el sector Sudeste de la rama castellana de la Cordillera Ibérica (Provincias de Cuenca y de Valéncia). Estudios Geológicos, nº. 42, pp. 123-143. Madrid

MATA-PERELLÓ, J.M. (1984).- Els Minerals del País Valencià, Col-lecció Informe, nº 6, 546 pàgines. Manresa

MATA-PERELLÓ, J.M. (1996).-Recerca Geològica i Mineralògica per I'Alt Palància i per la Plana Baixa: des de Sot de Ferrer a Soneixer, Xóvar, Eslida i a Betxí. Revista XARAGALL, Sèrie B. $n^{\circ} 30,10$ pag. Manresa

MATA-PERELLÓ, J.M. (2003).-Recerca Geològica i Mineralògica per les comarques de I'Alt Palància, el Camp de Morvedre i per la Plana Baixa: des de Sot de Ferrer a Assuévar, Soneixer, Xóvar, Eslida, Artana i a Betxí. 12 pàgines. Inèdit. Manresa

MATA-PERELLÓ, J.M. (2004).- Recerca geològica i mineralògica per I'Alt Palància, el Camp de Morvedre i per la Plana Baixa: de Sot de Ferrer i Algar de Palància a la Fondeguilla, Xóvar, Eslida i Artana. Inèdit, 12 pag. Manresa

MATA-PERELLÓ, J.M. i VILALTELLA FARRÀS, J. (2010).- Recerca geològica i mineralògica per l'Alt Palància, el Camp de Morvedre i per la Plana Baixa: de Sot de Ferrer i Algar de Palància a la Fondeguilla, Xóvar i a Eslida. Inèdit. 12 pàgines. Manresa

MATA-PERELLÓ, J.M. i VILALTELLA FARRÀS, J. (2013).- Recerca geològica i mineralògica per les comarques de l'Alt Palància, del Camp de Morvedre i per la Plana Baixa: des de Sot de Ferrer i Algar de Palància a Sonèixer / Soneja, Xóvar / Chovar i a Eslida. Inèdit- 16 pàgines. Manresa

MATA-PERELLÓ, J.M. et altri (2013).- Recerca geològica i mineralògica per la comarca de l'Alt Palància: des de Sot de Ferrer i Segorbe / Sogorb a la Vall de Almonacid, Navajas, Jérica / Xérica, Caudiel, a Higueras / Figueres i a Pavías / Pavíes. Inèdit. 17 pàgines. Manresa

MATA-PERELLÓ, J.M. i SANZ BALAGUER, J. (1988).- Guia de determinació de Minerals, adaptada als Països Catalans. Parcir, Edicions Selectes, 207 pàgines. Manresa

MATA-PERELLÓ, J.M. et altri (2012).- El patrimonio minero de la comarca del Alto Palància (Castellón, Comunidad Valenciana, Sistema Ibérico). Actas del XIII Congreso internacional sobre patrimonio geològico y minero, pp. 743 - 752. Manresa

RIBA, O. et altri (1976).- Geografia Física dels Països Catalans. Edit. Ketres, 254 pàgines. Barcelona

TRITLLA i CAMBRA,J. (1994).- Geologia y metalogenia de las mineralizaciones de Ba-Hg de la Serra de I'Espadà (Provincia de Castellón). Universitat Autònoma de Barcelona, 235 pàgines. Bellaterra 